\title{
Impact of sputum bacteria on airway inflammation and health status in clinical stable COPD
}

\author{
D. Banerjee*,\#, O.A. Khair*, D. Honeybourne
}

Impact of sputum bacteria on airway inflammation and health status in clinical stable COPD. D. Banerjee, O.A. Khair, D. Honeybourne. (C) ERS Journals Ltd 2004.

ABSTRACT: Chronic obstructive pulmonary disease (COPD) is characterised by sputum production, bacterial colonisation, neutrophilic bronchial airway inflammation and poor health status. The aim of this study was to determine the impact of sputum potentially pathogenic microorganisms (PPMs) on bronchial airway inflammation, health status and plasma fibrinogen levels in subjects with moderate-to-severe COPD during the clinical stable state.

Sputum total cell and neutrophil counts, supernatant interleukin-8, leukotriene $\mathbf{B}_{\mathbf{4}}$, tumour necrosis factor- $\alpha$ and neutrophil elastase levels, neutrophil chemotaxis and plasma fibrinogen levels were estimated. Health status was determined using the $\mathbf{S t}$ George's Respiratory Questionnaire and the 36-item Short-Form Health Survey questionnaire.

Twenty-seven $(40 \%)$ subjects had PPMs and $40(60 \%)$ non-PPMs in their sputum. Both groups were of similar age, body mass index, smoking history and lung function. The PPMs group showed significantly higher levels of interleukin-8, leukotriene $B_{4}$, tumour necrosis factor- $\alpha$, neutrophil elastase and increased neutrophil chemotaxis. They also exhibited worse health status and raised plasma fibrinogen levels compared to the non-PPMs group.

In conclusion, subjects with clinically stable moderate-to-severe chronic obstructive pulmonary disease who had potentially pathogenic microorganisms in their sputum demonstrated an exaggerated airway inflammatory response, poorer health status and increased plasma fibrinogen levels than those who had nonpotentially pathogenic microorganisms.

Eur Respir J 2004; 23: 685-691.
*Dept of Respiratory Medicine, City Hospital, and " Dept of Respiratory Medicine, Birmingham Heartlands Hospital, Birmingham, UK.

Correspondence: D. Honeybourne, Dept of Respiratory Medicine, Birmingham Heartlands Hospital, Bordesley Green East, Birmingham B9 5SS, UK.

Fax: 441217720292

E-mail: david.honeybourne@heartsol.wmids. nhs.uk

Keywords: Bacteria

chronic obstructive pulmonary disease

health status

inflammation

Received: May 212003

Accepted after revision: December 62003
The presence of bacteria in the lower bronchial airways of patients with stable chronic obstructive pulmonary disease (COPD) has been labelled as colonisation. There is ongoing debate as to whether bronchial inflammation in the presence of bacteria is truly colonisation. The presence of bacteria is abnormal as the lower respiratory tract, in the absence of lung disease, is normally sterile. Bronchoscopic techniques for the study of infections in COPD have confirmed that stable patients often carry bacteria in the lower respiratory tract, and multiple strains, such as nontypeable Haemophilus influenzae, Streptococcus pneumoniae and Moraxella catarrhalis, may be present [1-4].

A relationship between the intensity of sputum bacterial load and sputum inflammatory markers has been shown in stable patients with COPD [5]. Another study using bronchoalveolar lavage (BAL) found that patients with potentially pathogenic microorganisms (PPMs) had more neutrophils in BAL samples compared to those who had non-PPMs [6]. These studies, therefore, provide evidence that patients with stable COPD who show bacterial colonisation may have a more intense inflammatory response. How an exaggerated inflammatory response, as a result of bronchial airway PPMs colonisation, in the clinical stable state leads to the worsening of health status remains unclear.

A number of studies in COPD have suggested the possibility of a hypercoagulable state, with increased abnormalities

For editorial comments see page 657. of haemostasis. Raised fibrinogen and D-dimer levels have been reported in patients with COPD [7]. Fibrinogen levels have also been shown to be raised in patients with exacerbations of COPD, and there is some evidence that this may be associated with interleukin (IL)-6 production [8]. The effect of sputum PPMs colonisation on plasma fibrinogen levels in stable patients with moderate-to-severe COPD remains uncertain. The aim of the present study was to determine whether patients with COPD harbouring PPMs in their sputum during the clinical stable state have different degrees of airway inflammation, health status and plasma fibrinogen level compared to those stable patients with nonPPMs.

\section{Materials and methods}

\section{Study subjects}

An observational study was undertaken. Sixty-seven subjects with clinically stable moderate-to-severe COPD, in accordance with British Thoracic Society/Association of Respiratory Technicians and Physiologists guidelines [9], were recruited from City Hospital and Birmingham Heartlands Hospital (both Birmingham, UK) clinics and lung function units. All subjects had a forced expiratory volume in one second (FEV1)/forced vital capacity (FVC) ratio of $<70 \%$, an FEV 1 of $<60 \%$ of the predicted value and FEV1 reversibility 
of $<200 \mathrm{~mL}$ or $<15 \%$ (of baseline) to a $\beta_{2}$-agonist bronchodilator. Current smokers were regarded as those who had smoked regularly for $\geqslant 6$ months before the recruitment date and exsmokers as those who had stopped smoking regularly for $>6$ months before recruitment. Subjects with a recent infective exacerbation within the last 6 weeks or a clinical history of asthma, bronchiectasis, lung cancer and uncontrolled ischaemic heart disease or diabetes mellitus were excluded. Based on observations that many moderateto-severe patients in clinical practice are on inhaled corticosteroids and the growing evidence that withdrawal of these may have a detrimental effect on clinical state [10, 11], it was decided that only those subjects taking inhaled corticosteroids should be recruited. Informed consent was obtained from all subjects and the study was approved by the City Hospital and Birmingham Heartlands Hospital ethics committees.

\section{Study design}

The present observational study assessed the impact of PPMs in the sputum of subjects with clinically stable moderate-to-severe COPD on bronchial airway inflammation, health status and plasma fibrinogen levels compared to subjects with non-PPMs.

\section{Clinical measurements}

Spirometry (FEV1, FVC and FEV1/FVC) was performed using a MIR Spirobank (Medical International Research, Rome, Italy; accuracy $\pm 3 \%$; flow range $\left.\pm 16 \mathrm{~L} \cdot \mathrm{s}^{-1}\right)$. Reversibility of FEV1 was assessed by repeating spirometric tests $20 \mathrm{~min}$ after inhalation of salbutamol $(400 \mu \mathrm{g})$, given through a volume spacer by a trained member of the lung function department. Static lung volumes were measured at the City Hospital lung function unit by body box and gas transfer using the single-breath carbon monoxide method (V6200 Autobox; Sensormedics, Bilthoven, the Netherlands). Health status was measured using the St George's Respiratory Questionnaire (SGRQ) for disease-specific assessment of symptoms, activity and impact. The 36-item Short-Form Health Survey questionnaire (SF-36) was also used as a general health measure, covering eight health concepts: physical functioning, social functioning, physical role limitation, emotional role limitation, mental health, pain index, vitality, and general health perception. Fibrinogen levels (Klauss method), plasma viscosity using a Beckman Coulter Viscometer (Beckman Coulter, Inc., Fullerton, CA, USA) and C-reactive protein (CRP) levels were measured by the local hospital haematology and biochemistry departments respectively.

\section{Airway inflammation markers}

All subjects underwent hypertonic (3\%) saline sputum induction using a DeVilbiss ultrasonic nebuliser (DeVilbiss, Somerset, PA, USA; output $2.2 \mathrm{~mL} \cdot \mathrm{min}^{-1}$ ) as described previously [12]. All samples had a squamous cell count of $<30 \%$ of total and were therefore regarded as being adequate for cellular assessment. A portion of this sample was separated at this stage and saved for bacteriological assessment. Sputum plugs were separated from contaminating saliva by macroscopic examination using a pair of disposable plastic forceps with the aid of a hand-held lens. Processing the sputum for inflammatory markers included the use of $0.1 \%$ dithiothreitol solution as a mucolytic agent. From the resulting cell pellet, the total cell count was determined with a Neubauer haemocytometer, using the trypan blue exclusion method to determine cell viability. The cell pellet was rediluted in phosphate-buffered saline $(\mathrm{pH} \mathrm{7.4)}$ to give a final concentration $\sim 1 \times 10^{6}$ cells $\cdot \mathrm{mL}^{-1}$. Cytospin preparations were performed using a Cyto-tek centrifuge (Cyto-tek, Sakura-Finetek Europe, Zoeterwoude, the Netherlands). Cell suspension $(75 \mu \mathrm{L})$ was placed in the chamber holder and centrifuged for $5 \mathrm{~min}$ at $28.2 \times \mathrm{g}$. An even spread of cell suspension on the slide was obtained. The slide was left to air dry for $1 \mathrm{~h}$ and then stained using May-Grünwald-Giemsa. Once dried, the slide was mounted with distyrene/plasticiser/ xylene glue using a coverslip. In order to obtain a differential cell count, 400 cells were counted at a magnification of $\times 40$ using a multiple counter device, and the percentages of neutrophils, macrophages, eosinophils and lymphocytes (i.e. excluding squamous and epithelial cells) were obtained.

The supernatant recovered from the sputum processing was decanted and stored at $-70^{\circ} \mathrm{C}$ and later analysed for IL-8, leukotriene (LT) $\mathrm{B}_{4}$, tumour necrosis factor- $\alpha(\mathrm{TNF}-\alpha)$ and neutrophil elastase (NE). IL- 8 and TNF- $\alpha$ were measured by enzyme-linked immunosorbent assay (ELISA) using a commercially available kit (R\&D Systems Europe, Abingdon, UK). $\mathrm{LTB}_{4}$ was also measured using a commercially available ELISA kit (Amersham International, Amersham, UK). NE activity was measured spectrophotometrically using the synthetic substrate $N$-succinyl-Ala-Ala-Ala- $p$-nitroanilide as previously described by MCGILLIVRAY et al. [13]. The intraand interassay coefficient of variation $(\mathrm{CV})$ for these assays have previously been shown to be $<10 \%$ [14]. In the current study, the lower limits of detection were as follows: IL-8 $0.0125 \mathrm{nM} ; \quad \mathrm{LTB}_{4} 0.137 \mathrm{nM} ; \quad \mathrm{TNF}-\alpha \quad 0.1 \mathrm{pM}$; and NE $0.01 \mu \mathrm{M}$; all values below these limits were regarded as zero. The intra- and inter-assay CVs were: IL- $8<9 \%$; $\mathrm{LTB}_{4}$ $<10 \%$; TNF- $\alpha<10$ and $<15 \%$ respectively; and NE $<5 \%$.

Neutrophil chemotaxis was assessed using modified techniques described previously by FALK et al. [15] and HARVATH et al. [16]. In brief, this technique required a 48-well chamber unit (Neuro Probe $\AA 48$ Well Chemotaxis chamber; Neuro Probe, Inc., Cabin John, MD, USA) consisting of a top and bottom acrylic plate, a sealing silicone gasket and assembly hardware. The lower plate comprised 48 wells, each $25 \mu \mathrm{L}$ in volume. Corresponding holes in the top plate formed the upper wells of $50 \mu \mathrm{L}$ in volume. A single filter membrane

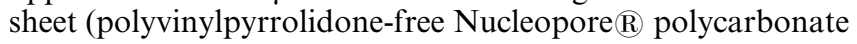
filter; Costar, High Wycombe, UK) containing 2- $\mu \mathrm{m}$ pores was used to separate the two plates. Neutrophils were initially purified from peripheral blood by means of discontinuous Percoll density gradients using the method described by JEPSEN and SKOTTUN [17]. The neutrophil chemotaxis assay was carried out in triplicate; $27.5 \mu \mathrm{L}$ chemoattractant was pipetted into the lower chamber to obtain a meniscus and $50 \mu \mathrm{L}$ neutrophils into the upper chamber, and the chamber unit incubated for $20 \mathrm{~min}$ at $37^{\circ} \mathrm{C}$. The assay kit was disassembled and the membrane sheet carefully removed, air dried for $1 \mathrm{~h}$ and then stained using DiffQuik dyes (methanol fixative, eosin $\mathrm{G}$ and thiazine). Neutrophils were counted at a magnification of $\times 40$. For each well (of the triplicate), cells wholly contained within five random half-pitch fields were counted and the mean taken. Neutrophil migration was expressed as a percentage of that in response to a positive control of $1 \times 10^{-8} \mathrm{M} \mathrm{N}$-formyl-methionyl-leucyl-phenylalanine. The intra-assay CV was $8 \%$.

\section{Quantitative bacterial load assay}

Quantitative bacterial culture measurements on the sputum were carried out as previously described by PYE et al. [18]. All samples were processed for bacteriology within $4 \mathrm{~h}$ of expectoration. Viable bacterial numbers were expressed as the 
number of colony-forming units (cfu) per millilitre of original sputum. Bacterial pathogens recovered were classified as PPMs and nonpathogens as non-PPMs, as previously described by SOLER et al. [6]. PPMs included respiratory bacterial pathogens, e.g. H. influenzae, S. pneumoniae, M. catarrhalis, H. parainfluenzae, Staphylococcus aureus, Pseudomonas aeruginosa and Klebsiella pneumoniae, and the following were regarded as non-PPMs: Streptococcus viridans, Neisseria spp., Corynebacterium spp., Candida spp., Enterococcus spp., and coagulase-negative Staphylococcus. The impact of sputum PPMs and non-PPMs on airway inflammation, health status and plasma fibrinogen levels were compared as groups rather than as individual bacterial species. Bacterial colonisation studies were performed by technical staff blind to the clinical characteristics of the subjects in the study.

\section{Statistical analysis}

In order to determine whether the distributions of all continuous data were normal, a Kolmogorov-Smirnov test was performed. In cases in which such an assumption could not be met for bacterial cfus and airway inflammatory cell counts, data were logarithmically transformed and presented as mean \pm SEM. Nonparametric health status data are presented as median and interquartile range (IQR). Continuous variables with normal distributions were compared using the parametric unpaired two-independent-group t-test, whereas those data not normally distributed were compared using the nonparametric Mann-Whitney U-test. Correlations between parametric data were undertaken using Pearson's correlation and nonparametric data using Spearman's rank correlation. Two-tailed tests were used and the level of significance was taken as $\mathrm{p}<0.05$.

\section{Results}

Twenty-seven $(40 \%)$ subjects had PPMs in their sputum as opposed to $40(60 \%)$ who had non-PPMs. Fourteen $(52 \%)$ and $13(32 \%)$ subjects from the PPMs and non-PPMs groups

Table 1. - Clinical demographic data for subjects with sputum potentially pathogenic microorganisms (PPMs) and nonPPMs

\begin{tabular}{lcc}
\hline & PPMs & Non-PPMs \\
\hline Subjects n & 27 & 40 \\
Age yrs & $67.5 \pm 1.5$ & $66.2 \pm 1.2$ \\
BMI kg.m ${ }^{-2}$ & $23.2 \pm 0.8$ & $25.3 \pm 1.0$ \\
Cigarette consumption pack-yrs & $62.1 \pm 4.8$ & $56.4 \pm 4.0$ \\
FEV1 L & $1.08 \pm 0.07$ & $1.15 \pm 0.07$ \\
\% pred & $40.3 \pm 1.9$ & $45.2 \pm 1.9$ \\
FVC L & $2.60 \pm 0.16$ & $2.52 \pm 0.13$ \\
\% pred & $77.7 \pm 3.3$ & $77.5 \pm 2.6$ \\
FEV1/FVC \% & $42.1 \pm 1.9$ & $46.5 \pm 1.9$ \\
TLC \% pred & $110.8 \pm 2.9$ & $110.0 \pm 3.0$ \\
RV \% pred & $167.4 \pm 8.1$ & $169.6 \pm 8.0$ \\
RV/TLC \% pred & $146.7 \pm 4.9$ & $149.8 \pm 4.5$ \\
DL,CO \% pred & $53.2 \pm 3.4$ & $49.4 \pm 2.5$ \\
KCO \% pred & $68.1 \pm 3.5$ & $66.8 \pm 2.8$ \\
CRP mg $\cdot \mathrm{dL}^{-1}$ & $7(5-11)$ & $5(5-8)$ \\
\hline
\end{tabular}

Data are presented as mean \pm SEM or median (interquartile range). BMI: body mass index; FEV1: forced expiratory volume in one second; FVC: forced vital capacity; TLC: total lung capacity; RV: residual volume; $D \mathrm{~L}, \mathrm{CO}$ : carbon monoxide diffusing capacity of the lung; $\mathrm{KCO}$ : carbon monoxide transfer coefficient; CRP: C-reactive protein; \% pred: per cent predicted. All differences were nonsignificant. respectively were current smokers ( $\mathrm{p}=0.47$ ) The demographics of the PPMs and non-PPMs groups are shown in table 1. There were no significant differences between the two groups with regard to age, body mass index, smoking history, lung function or C-reactive protein levels.

\section{Sputum bacteriology}

There were a total of 38 bacterial isolates from the PPMs group. Ten subjects in this group yielded more than one bacterial isolate in their sputum. The PPM species isolated are shown in table 2. $H$. influenzae, $M$. catarrhalis and $S$. pneumoniae made up $91 \%$ of all bacterial isolates.

\section{Sputum airway inflammatory mediators}

Subjects with PPMs in their sputum exhibited higher neutrophil numbers (although this did not quite reach significance), a higher neutrophil differential, higher supernatant levels of IL-8 (fig. 1a), LTB 4 (fig. 1b), TNF- $\alpha$ (fig. 1c) and NE (fig. 1d), and a more exaggerated neutrophil chemotactic response than those subjects who had nonPPMs in their sputum. These results are summarised in table 3 . Inflammatory parameters were logarithmically transformed for sputum total cell count and absolute neutrophil count. In the PPM group, correlation studies between log total cfus (i.e. bacterial load) for each subject sputum sample and sputum inflammatory markers revealed significant relationships for IL-8 ( $\mathrm{r}=0.51, \mathrm{p}=0.007), \mathrm{LTB}_{4} \quad(\mathrm{r}=0.49$, $\mathrm{p}=0.01)$ and TNF $-\alpha(\mathrm{r}=0.57, \mathrm{p}=0.002)$. No significant relationship existed between bacterial load and sputum neutrophil count or neutrophil chemotaxis.

\section{Health status, fibrinogen level and plasma viscosity}

Subjects with PPMs in their sputum demonstrated worse health status than subjects with non-PPMs in the following scores: SGRQ total $(\mathrm{p}=0.004)$, SGRQ impact $(\mathrm{p}=0.005)$, SGRQ symptoms ( $\mathrm{p}=0.03)$, SGRQ activity $(\mathrm{p}=0.004), \mathrm{SF}-36$ vitality $(\mathrm{p}=0.02)$ and $\mathrm{SF}-36$ physical role limitation $(\mathrm{p}=0.03)$ (table 4). Bacterial load did not correlate with any health status parameter.

There was no difference in plasma viscosity between the PPMs and non-PPMs groups. Those with PPMs, however, showed a significantly increased level of plasma fibrinogen $(\mathrm{p}=0.05)$ (table 4). There was no significant correlation between bacterial load and plasma fibrinogen levels in the PPMs group.

Table 2.-Potentially pathogenic microorganisms ${ }^{\#}$

Isolates $\mathrm{n}$ Bacterial load $\log \mathrm{cfu} \cdot \mathrm{mL}^{-1}$

\begin{tabular}{lrc}
\hline Haemophilus influenzae & 14 & $8.59 \pm 0.35$ \\
Moraxella catarrhalis & 10 & $8.31 \pm 0.39$ \\
Streptococcus pneumoniae & 9 & $8.47 \pm 0.30$ \\
Staphylococcus aureus & 1 & 9.46 \\
Klebsiella pneumoniae & 1 & 7.30 \\
Pseudomonas aeruginosa & 1 & 7.60 \\
Coliform & 1 & 8.36 \\
Acinetobacter baumannii & 1 & 9.34
\end{tabular}

Data are presented as mean \pm SEM or absolute numbers. * : isolated from the sputum of 27 subjects. 

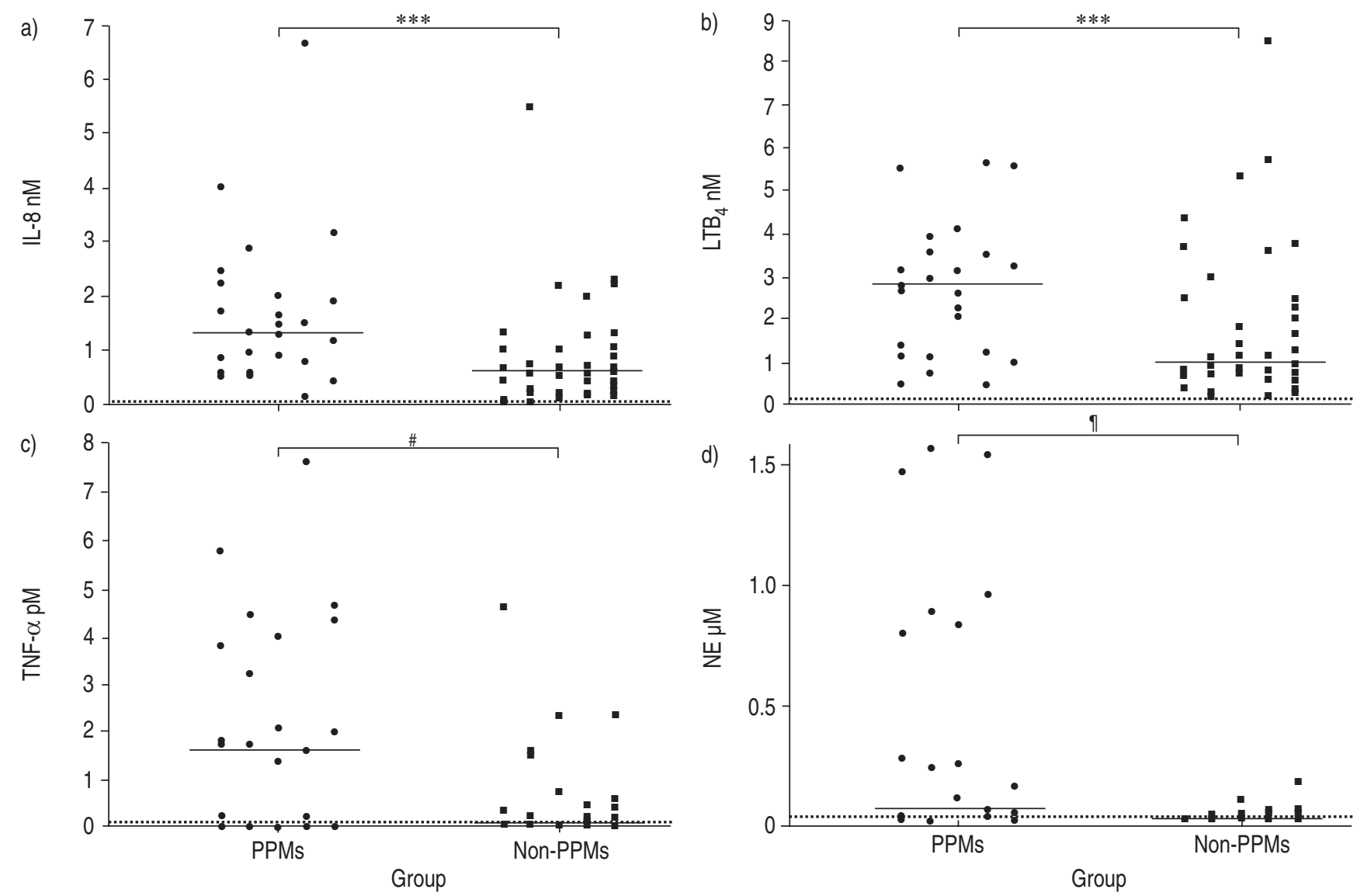

Fig. 1. - Supernatant a) interleukin (IL)-8, b) leukotriene (LT) $\left.B_{4}, c\right)$ tumour necrosis factor- $\alpha$ (TNF- $\alpha$ ) and d) neutrophil elastase (NE) in the potentially pathogenic microorganism (PPMs) and non-PPMs groups. Horizontal bars indicate medians ( ....... lower limit of detection). ${ }^{\#}$ : $\mathrm{p}=0.006 ;$; $\mathrm{p}=0.005 ; * * *: \mathrm{p}=0.001$.

\section{Discussion}

The present study has shown that subjects with moderateto-severe COPD who have PPMs in their sputum have an exaggerated airway inflammatory response, worse health status and higher levels of plasma fibrinogen compared to subjects who have non-PPMs in their sputum, even in the clinical stable state.

The precise role of bacteria in COPD has been a source of controversy for many years. The current study found that $40 \%$ of subjects had PPMs in their sputum, and the commonest microorganisms isolated were $H$. influenzae, $M$. catarrhalis and $S$. pneumoniae. This compares favourably with previous findings [2, 6, 19]. There were four Gram-negative isolates from three subjects in the current study: $K$. pneumoniae, $P$. aeruginosa, a coliform and Acinetobacter baumannii. These three subjects had an FEV1 of 33-41\% pred. A previous study suggested that exacerbations in patients with COPD at the severe end of the spectrum (as assessed by FEV1 as a percentage of the predicted value) are more likely to be caused by such Gram-negative organisms [20]. There was no relation, however, between pulmonary lung function and sputum PPMs colony-forming unit numbers in the present study.

Subjects who had non-PPMs (such as S. viridans, Neisseria spp., Corynebacterium spp. and coagulase-negative Staphylococcus)

Table 3. - Comparison of sputum airway inflammatory parameters between subjects with potentially pathogenic microorganisms (PPMs) and non-PPMs

\begin{tabular}{|c|c|c|c|}
\hline & PPMs & Non-PPMs & p-value \\
\hline Subjects $\mathrm{n}$ & 27 & 40 & \\
\hline TCC log TCC $\cdot g$ sputum ${ }^{-1}$ & $6.74 \pm 0.08$ & $6.54 \pm 0.09$ & 0.072 \\
\hline Neutrophils $\log$ neutrophils.g sputum ${ }^{-1}$ & $6.71 \pm 0.08$ & $6.50 \pm 0.09$ & 0.058 \\
\hline Neutrophil differential \% & $92.7 \pm 0.8$ & $90.0 \pm 0.8$ & 0.026 \\
\hline IL-8 nM & $1.34(0.61-2.01)$ & $0.62(0.22-1.05)$ & 0.001 \\
\hline $\mathrm{LTB}_{4} \mathrm{nM}$ & $2.79(1.18-3.54)$ & $1.00(0.71-2.44)$ & 0.008 \\
\hline TNF- $\alpha$ pM & $1.62(0-3.75)$ & $0.07(0-0.33)$ & 0.006 \\
\hline $\mathrm{NE} \mu \mathrm{M}$ & $0.05(0-0.77)$ & $0(0-0.02)$ & 0.005 \\
\hline NC $\%$ fMLP & $70.4 \pm 3.29$ & $54.6 \pm 3.65$ & 0.001 \\
\hline
\end{tabular}

Data are presented as mean \pm SEM or median (interquartile range). TCC: total cell count; IL: interleukin; LT: leukotriene; TNF- $\alpha$ : tumour necrosis factor- $\alpha$; NE: neutrophil elastase; NC: neutrophil chemotaxis; fMLP: $N$-formyl-methionyl-leucyl-phenylalanine. 
Table 4.-Comparison of health status scores and plasma fibrinogen levels and viscosity between subjects with potentially pathogenic microorganisms (PPMs) and nonPPMs

\begin{tabular}{lccc}
\hline & PPMs & Non-PPMs & p-value \\
\hline SGRQ & & & \\
$\quad$ Total & $58.7 \pm 2.8$ & $47.4 \pm 2.5$ & 0.004 \\
Impact & $46.1 \pm 3.1$ & $34.1 \pm 2.7$ & 0.005 \\
$\quad$ Symptoms & $70.3 \pm 2.8$ & $60.5 \pm 3.4$ & 0.03 \\
$\quad$ Activity & $76.8 \pm 3.3$ & $63.2 \pm 3.2$ & 0.004 \\
SF-36 & $55.6 \pm 6.8$ & $78.5 \pm 4.8$ & $\mathrm{NS}$ \\
$\quad$ Social functioning & $31.1 \pm 3.4$ & $43.0 \pm 3.7$ & 0.02 \\
Vitality & $37.2 \pm 4.2$ & $36.7 \pm 3.5$ & $\mathrm{NS}$ \\
$\quad$ General health perception & $58.4 \pm 6.0$ & $63.4 \pm 4.0$ & $\mathrm{NS}$ \\
Bodily pain & $68.9 \pm 4.3$ & $67.8 \pm 3.0$ & $\mathrm{NS}$ \\
Mental health & $0(12-100)$ & $0(0-81)$ & 0.03 \\
Physical role limitation & $66(33-100)$ & $100(33-100)$ & $\mathrm{NS}$ \\
$\quad$ Emotional role limitation & & & \\
Plasma & $1.74 \pm 0.03$ & $1.71 \pm 0.02$ & $\mathrm{NS}$ \\
$\quad$ Viscosity mPa $\cdot \mathrm{s}^{-1}$ & $3.21 \pm 0.16$ & $2.85 \pm 0.10$ & 0.05 \\
Fibrinogen $\mathrm{g} \cdot \mathrm{L}^{-1}$ & & & \\
\hline
\end{tabular}

Data are presented as mean \pm SEM or median (interquartile range). SGRQ: St George's Respiratory Questionnaire; SF-36: 36-item ShortForm Health Survey questionnaire. NS: nonsignificant.

in their sputum interestingly showed an inflammatory response, although levels of supernatant cytokines were lower than in those subjects with PPMs. There were fewer neutrophils in the sputum of subjects with non-PPMs, but this did not quite reach significance. The perception of what is pathogenic can change. For example, $M$. catarrhalis was not regarded as a pathogen for many years and there is little information about the propensity of different non-PPMs species to stimulate bronchial inflammation [21]. In the current work, differentiation between non-PPMs species and their relationship to airway inflammation and health status was not carried out; instead they were analysed as a group. It may also be possible that certain subjects with non-PPMs had negative sputum cultures to PPMs which could have been detected by other methods, e.g. bronchoalveolar lavage (BAL). Sputum culture has been shown to be a reliable method of obtaining microbiological data [22]. However, the present study seems to suggest that a chronic inflammatory response in moderate-to-severe COPD is present despite the absence of PPMs in the sputum. Indeed, Hill et al. [5] have shown that non-PPMs generate similar levels of IL- 8 to $1 \times 10^{5}$ $\mathrm{cfu} \cdot \mathrm{mL}^{-1}$ PPMs in subjects with COPD.

In the current research, subjects with PPMs had worse health status scores than those with non-PPMs. There was a significant difference between the two groups in all SGRQ components ( $p$-value $0.005-0.03$ ) and SF-36 physical role limitation and vitality ( $\mathrm{p}=0.03$ and 0.02 respectively). There was, however, no numerical difference between the SF-36 physical role limitation medians and hence its biological significance is doubtful. The mean differences in SGRQ score ranged 9.9-13.6, illustrating that the differences were greater than the 4 scale points that are regarded as clinically meaningful. These particular data have not been shown before in the literature and illustrate that the presence of bacteria in sputum, even when subjects are in the clinical stable state, has a significant impact on health status.

The mechanism of this difference in health status cannot be explained solely on the basis of differences in lung function as both groups in this study were similar in this respect. However, it is possible that bacteria cause a worse health status by inducing an exaggerated inflammatory response. This was demonstrated by the current data in that there were more sputum neutrophils in those with PPMs (although this did not quite reach significant levels $(\mathrm{p}=0.058)$ ) and also significantly higher levels of supernatant IL-8, LTB $4, \mathrm{TNF}-\alpha$, $\mathrm{NE}$ and neutrophil chemotaxis than in those with non-PPMs. There is also some evidence from ANGRILL et al. [23] that patients with bronchiectasis colonised by such non-PPMs exhibit a reduced inflammatory response in terms of reduced absolute neutrophil counts and IL-8, IL-6, TNF- $\alpha$ and NE levels. Neutrophils in sputum may lead to activation of other inflammatory cells in the lung, leading to the release of systemic pro-inflammatory proteins/cytokines, which eventually lead to systemic ill-health, e.g. skeletal muscle dysfunction, abnormal nutrition and metabolism, etc., which would impact on symptoms. It may be argued that the presence of neutrophils in the sputum is a normal response to the original bacterial insult to the bronchial airways. In the present study, no difference was seen in the levels of CRP between both groups and mean levels were within the normal range. This indicates that there was probably no acute systemic clinical state present in the two groups, although a bronchial inflammatory response was detectable from sputum measurements. These results may reflect the "compartmentalised" nature of COPD airway inflammation in those subjects who are in the clinical stable state.

It is possible that the subjects in the PPMs group represent "frequent exacerbators" (as opposed to "infrequent exacerbators"). Subjects with frequent exacerbations have worse health status [24] and increased levels of sputum IL-6 and IL8 compared to those subjects with infrequent exacerbations [25]. Moreover, patients with frequent exacerbations also demonstrate a faster decline in FEV1 than infrequent exacerbators, with exacerbations contributing to $\sim 25 \%$ of the observed lung function decline in subjects with COPD [26]. More recently, it has been demonstrated that there is a significant relationship between sputum bacterial load and disease progression in subjects with COPD, showing that the rate of decline in FEV1 is proportional to the rise in colonising bacterial load [27].

The exacerbation rate during the preceding year in subjects in the current study was determined by their recalling the number of times their symptoms worsened and resulted in a visit to their primary care physician for antibiotics and oral corticosteroids. Recall accuracy may be questioned as there was no objective evidence of symptoms in this preceding year, e.g. diary cards. In the present study, however, subjects with PPMs reported a higher median exacerbation rate (median 2, IQR 1-2) compared to subjects with non-PPMs (median 1, IQR 0-2), although this just failed to achieve significance $(\mathrm{p}=0.09)$.

If the frequency of exacerbations between the PPMs and non-PPMs groups in the current study is truly not different, it is possible that what determines inflammation and health status at any particular point in time is not the number of exacerbations in the preceding year but the current qualitative and quantitative PPMs colonisation state.

The interactions between inhaled corticosteroids, airway inflammation and infective exacerbations remain complex and have yet to be fully evaluated. The influence of inhaled corticosteroids on morbidity and mortality has been debated elsewhere [28], and previous studies assessing the effect of inhaled corticosteroids on airway inflammation have been mixed [29-32]. A more recent study, however, has shown that inhaled corticosteroids may attenuate the secretion of IL-8 and IL-6 from cultured bronchial epithelial cells when stimulated by TNF- $\alpha$ [33]. In the current study, all patients recruited were taking inhaled corticosteroids. The impact of inhaled corticosteroid therapy on airway inflammation generated by bacterial colonisation is unclear. Further sequential studies investigating the impact of bronchial 
airway colonisation on airway inflammatory markers, health status and FEV1 decline in patients receiving or not receiving inhaled corticosteroid therapy during the clinical stable state may be necessary.

The present study also found increased levels of plasma fibrinogen in subjects with PPMs compared to those with non-PPMs. Raised fibrinogen levels have been found in stable patients and increase during an acute exacerbation [8]. This increment in fibrinogen level was similar to the difference in level between the two groups in this current study, even during the stable state. The cohort of subjects in this previous study was also similar to the current study with regard to spirometric results. The exact mechanism of fibrinogen level increase in COPD is unclear, but it is hypothesised that it may be mediated through IL-6 [8]. It is possible that airway bacterial colonisation leads to enhanced release of IL-6, causing raised fibrinogen levels. Increased fibrinogen levels in the stable state, which theoretically translate into a prothrombotic state, raises the question of long-term anticoagulation in susceptible patients.

In summary, the current study showed that those subjects with potentially pathogenic microorganisms in their sputum exhibited a higher level of airway inflammation, poorer health status and increased levels of plasma fibrinogen than subjects with nonpotentially pathogenic microorganisms during the clinical stable state. Further studies are needed to explain the interactions between bacterial colonisation, airway inflammation and health status in chronic obstructive pulmonary disease.

\footnotetext{
Acknowledgements. The authors would like to thank R. Stockley, S. Hill and D. Bayley for their advice and technical supervision of the laboratory procedures.
}

\section{References}

1. Monso E, Ruiz J, Rosell A, Manterola J, Fiz J, Morera J. Bacterial infection in chronic obstructive pulmonary disease. A study of stable and exacerbated outpatients using the protected specimen brush. Am J Respir Crit Care Med 1995; 152: 1316-1320.

2. Monso E, Rosell A, Bonet G, Manterola J, Cardona PJ, Ruiz J. Risk factors for lower airway bacterial colonization in chronic bronchitis. Eur Respir J 1999; 13: 338-342.

3. Cabello H, Torres A, Celis R, El Ebiary M, Puig D, Xaubet A. Bacterial colonization of distal airways in healthy subjects and chronic lung disease: a bronchoscopic study. Eur Respir $J$ 1997; 10: 1137-1144.

4. Murphy TF, Sethi S, Klingman KL, Brueggemann AB, Doern GV. Simultaneous respiratory tract colonization by multiple strains of nontypeable Haemophilus influenzae in chronic obstructive pulmonary disease: implications for antibiotic therapy. J Infect Dis 1999; 180: 404 409.

5. Hill AT, Campbell EJ, Hill SL, Bayley DL, Stockley RA. Association between airway bacterial load and markers of airway inflammation in patients with stable chronic bronchitis. Am J Med 2000; 109: 288-295.

6. Soler N, Ewig S, Torres A, Filella X, Gonzalez J, Zaubet A. Airway inflammation and bronchial microbial patterns in patients with stable chronic obstructive pulmonary disease. Eur Respir J 1999; 14: 1015-1022.

7. Alessandri C, Basili S, Violi F, Ferroni P, Gazzaniga PP, Cordova C. Hypercoagulability state in patients with chronic obstructive pulmonary disease. Chronic Obstructive Bronchitis and Haemostasis Group. Thromb Haemost 1994; 72: 343-346.

8. Wedzicha JA, Seemungal TA, MacCallum PK, Paul EA, Donaldson GC, Bhowmik A. Acute exacerbations of chronic obstructive pulmonary disease are accompanied by elevations of plasma fibrinogen and serum IL-6 levels. Thromb Haemost 2000; 84: 210-215.

9. Anon. BTS guidelines for the management of chronic obstructive pulmonary disease. The COPD Guidelines Group of the Standards of Care Committee of the BTS. Thorax 1997; 52: Suppl. 5, S1-S28.

10. Jarad NA, Wedzicha JA, Burge PS, Calverley PM. An observational study of inhaled corticosteroid withdrawal in stable chronic obstructive pulmonary disease. ISOLDE Study Group. Respir Med 1999; 93: 161-166.

11. Van der Valk P, Monninkhof E, Van der Palen J, Zielhuis G, van Herwaarden C. Effect of discontinuation of inhaled corticosteroids in patients with chronic obstructive pulmonary disease: the COPE study. Am J Respir Crit Care Med 2002; 166: 1358-1363.

12. Bhowmik A, Seemungal TA, Sapsford RJ, Devalia JL, Wedzicha JA. Comparison of spontaneous and induced sputum for investigation of airway inflammation in chronic obstructive pulmonary disease. Thorax 1998; 53: 953-956.

13. McGillivray DH, Burnett D, Afford SC, Stockley RA. An evaluation of four methods for the measurement of elastase activity. Clin Chim Acta 1981; 111: 289-294.

14. Stockley RA, Bayley DL. Validation of assays for inflammatory mediators in sputum. Eur Respir J 2000; 15: 778-781.

15. Falk W, Goodwin RH, Leonard EJ. A 48-well micro chemotaxis assembly for rapid and accurate measurement of leukocyte migration. J Immunol Methods 1980; 33: 239-247.

16. Harvath L, Falk W, Leonard EJ. Rapid quantitation of neutrophil chemotaxis: use of a polyvinylpyrrolidone-free polycarbonate membrane in a multiwell assembly. J Immunol Methods 1980; 37: 39-45.

17. Jepsen LV, Skottun T. A rapid one-step method for the isolation of human granulocytes from whole blood. Scand $J$ Clin Lab Invest 1982; 42: 235-238.

18. Pye A, Stockley RA, Hill SL. Simple method for quantifying viable bacterial numbers in sputum. J Clin Pathol 1995; 48: 719-724.

19. Zalacain R, Sobradillo V, Amilibia J, Barron J, Achotegui V, Pijoan JI. Predisposing factors to bacterial colonization in chronic obstructive pulmonary disease. Eur Respir J 1999; 13: $343-348$.

20. Eller J, Ede A, Schaberg T. Infective exacerbations of chronic bronchitis. Chest 1998; 113: 1542-1548.

21. Wilson R. Bacteria, antibiotics and COPD. Eur Respir J 2001; 17: 995-1007.

22. Angrill J, Agusti C, De Celis R, et al. Bacterial colonisation in patients with bronchiectasis: microbiological pattern and risk factors. Thorax 2002; 57: 15-19.

23. Angrill J, Agusti C, De Celis R, et al. Bronchial inflammation and colonization in patients with clinically stable bronchiectasis. Am J Respir Crit Care Med 2001; 164: $1628-1632$.

24. Seemungal TA, Donaldson GC, Paul EA, Bestall JC, Jeffries DJ, Wedzicha JA. Effect of exacerbation on quality of life in patients with chronic obstructive pulmonary disease. $\mathrm{Am}$ J Respir Crit Care Med 1998; 157: 1418-1422.

25. Bhowmik A, Seemungal TA, Sapsford RJ, Wedzicha JA. Relation of sputum inflammatory markers to symptoms and lung function changes in COPD exacerbations. Thorax 2000; 55: $114-120$

26. Donaldson GC, Seemungal TA, Bhowmik A, Wedzicha JA. Relationship between exacerbation frequency and lung function decline in chronic obstructive pulmonary disease. Thorax 2002; 57: 847-852.

27. Wilkinson TM, Patel IS, Wilks M, Donaldson GC, Wedzicha JA. Airway bacterial load and FEV1 decline in patients with chronic obstructive pulmonary disease. $\mathrm{Am}$ J Respir Crit Care Med 2003; 167: 1090-1095.

28. Samet JM. Measuring the effectiveness of inhaled corticosteroids for COPD is not easy! Am J Respir Crit Care Med 2003; 168: 1-2. 
29. Hattotuwa KL, Gizycki MJ, Ansari TW, Jeffery PK, Barnes NC. The effects of inhaled fluticasone on airway inflammation in chronic obstructive pulmonary disease: a doubleblind, placebo-controlled biopsy study. Am J Respir Crit Care Med 2002; 165: 1592-1596.

30. Keatings VM, Jatakanon A, Worsdell YM, Barnes PJ. Effects of inhaled and oral glucocorticoids on inflammatory indices in asthma and COPD. Am J Respir Crit Care Med 1997; 155: 542-548.

31. Culpitt SV, Maziak W, Loukidis S, Nightingale JA, Matthews JL, Barnes PJ. Effect of high dose inhaled steroid on cells, cytokines, and proteases in induced sputum in chronic obstructive pulmonary disease. Am J Respir Crit Care Med 1999; 160: 1635-1639.

32. Llewellyn-Jones CG, Harris TA, Stockley RA. Effect of fluticasone propionate on sputum of patients with chronic bronchitis and emphysema. Am J Respir Crit Care Med 1996; 153: 616-621.

33. Patel IS, Roberts NJ, Lloyd-Owen SJ, Sapsford RJ, Wedzicha JA. Airway epithelial inflammatory responses and clinical parameters in COPD. Eur Respir $J$ 2003; 22: 94-99. 